\title{
ISSUES OF PARTICIPANT ABSORPTIVE CAPACITY IN ESTABLISHING VIRTUAL ENTERPRISE OPERATIONS
}

\author{
Ronald C. Beckett \\ The Reinvention Network \& University of Western Sydney, rcb@reinvent.net.au \\ AUSTRALIA
}

\begin{abstract}
The author is involved in a multi-year program to establish a number of largescale SME collaboration projects. It was anticipated that some web-based tools used previously could be adapted, but limits in the participant firm capabilities and the emergence of a different business model led to a change in approach. In this paper an adaptation of the notion of absorptive capacity where both a firm's resource base and its knowledge base are considered is used as a framework to better understand participant requirements in building a web-based Virtual Enterprise support system.
\end{abstract}

\section{INTRODUCTION}

The author is involved in a multi-year program (called RELINK [9]) to establish a large-scale (20 - 100 SME manufacturing firms) Virtual Enterprise capability that enhances the market positioning of the participants. The intention is to draw together small firms who have been dislinked from their traditional supply chains and market access pathways due to some effects of globalization so they can access new, broader markets. This paper reports on some observations made over a period of two years where an action research style of interaction was the norm - trying out ideas from previous work, and using outcomes to frame new ideas.

Some management researchers see markets as intersecting networks of actors, activities and resources [www.impgroup.org]. In previous work [2] we have explored the business benefits arising from collaborative inter-firm transactions and compared a number of different instances using an activity theory framework [1]. Activity theory $[7,13]$ evolved from studies of learning by doing, and suggests a subject will undertake an activity with an objective in mind, and how this is achieved is governed by the distribution of work, tools available, rules associated with the activity and broader community norms. In this paper, we consider one particular aspect of a VE resource network - the uptake of ICT tools that facilitate VE task management, data management and communications. Within that resource network context however, we also have embedded networks of actors, activities and resources that support its operation. In this paper, the focus is on the capabilities of the VE partner enterprise as an actor within the resource network, where we observe that two things influence the style of participation:

- Some limitations on resources available to acquire new ICT tools. 
- Some limits on a firms' accessible knowledge to help use ICT tools, effectively

In an activity theory context, these two factors will influence what kinds of tools can be used in practice, but the framework provided by this theory does not help clarify the issues involved.

One objective of the RELINK program was to adapt research findings and system concepts from previous projects involving larger firms [15, 16] relating to the use of enabling Information Technology tools. A number of difficulties were experienced. One related to available infrastructure, and this has been discussed in a previous paper [8]. Another related to the ability of an individual firm to participate. In this paper we adapt the notion of absorptive capacity attributed to Cohen and Levinthal [3] to provide a framework for clarifying the issues to be addressed, and discuss subsequent actions in the RELINK project.

\section{SYSTEM CONCEPT}

The intended system model is illustrated in Figure 1. It is comprised of a number of reusable components (broadly identified under the headings of contingency factors, modeling, applications and infrastructure and methodology) and some components, models and knowledge specific to a particular VE (VE models and operational ICT environment). The system also embraced the notion of characterizing the establishment and operation of a VE using a life-cycle view (VERAM [15])

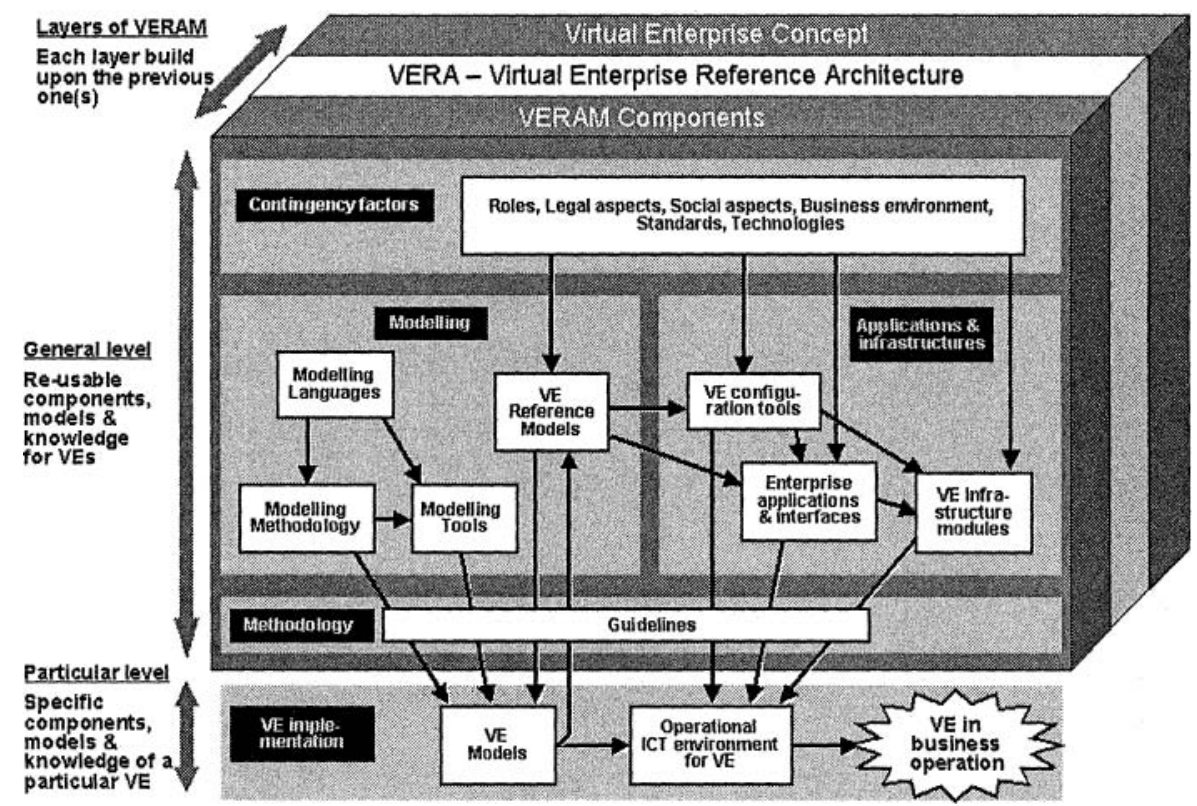

Figure 1 A technology enabled VE capability model 
This model can help us understand the position of each potential participant in respect of a number of required capabilities, with a view to building bridges to effective participation as required. It was observed however that embracing these ideas which appeared effective in previous work with large firms was too big a step for most small firms. The participating firms were not comfortable with complex models, even though they might help understand the range of matters to be dealt with in establishing a large-scale collaboration. A different way of packaging the same logical concept was pursued.

\section{ICT SUPPORT FOR SMALL COLLABORATING FIRMS AND SOME DIFFICULTIES EXPERIENCED}

Whilst IT tools are available to support large scale collaboration, there are issues of scale to be addressed. An example is Teamcenter [11] which is used to support product life-cycle management, but which is typically used by firms 100 times the size of the RELINK project target firms. The RELINK project participant firm size varied from many with less than 10 employees to a few firms having around 100 employees. Most of the firms were involved with the manufacture of production tooling, with each project commonly taking three to nine months to complete. IT capability varied widely between firms. Some firms have a website for advertising purposes, and a few use a password-accessible website facility to provide customers with job progress information. A few firms use ERP systems to manage the flow of work and to collect realistic cost data. Most customer product data is obtained in electronic form (CAD/CAM), and transformed into machine instructions for computer controlled machines to manufacture tooling and components. Microsoft Project software is commonly used by the larger firms for scheduling work and as a progress monitoring tool for customer reporting. Most firms will not have a resident IT specialist, and are not knowledgeable about communications technology. They are not knowledgeable about IT based collaboration technologies, although most use e-mail. The size of the participating firm's means that they do not have access lo a large amount of capital to buy IT equipment that is not central to money-making activities.

\section{ISSUES OF ABSORPTIVE CAPACITY}

The notion of absorptive capacity was introduced by Cohen and Levinthal [4] who defined it as 'the ability of an organisation to recognise the value of new, external information, assimilate it, and apply it to commercial ends'. They saw the acquisition of this capacity as linked to the R\&D capabilities of the organization.

In this paper we extend the theory in two ways. Firstly we take the view that the notion of absorptive capacity can be applied to a variety of capability acquisition situations and secondly we add consideration of resources that facilitate knowledge assimilation and application.

DalZotto [5] has applied the notion of absorptive capacity to a venture capital situation, and Tsai [12] has utilized the idea in better understanding intra- 
organizational knowledge transfer. Zahra and George [14] and Daghfous [5] extended the theory by specifying four distinct evolutionary stages of absorptive capacity development: knowledge acquisition, assimilation, transformation and exploitation that emerge chronologically in that order. Similar progressive stages were previously noted by Szulanski [10] in the transfer of best practice between different parts of a large enterprise. Szulanski observed 122 best practice transfers in eight companies, and noted a number of barriers to effective transfer. Three dominant factors were a lack of absorptive capacity, causal ambiguity (lack of understanding why something will work in one place but not another) and an arduous relationship between the source and the recipient (too many handovers distort the content or a source in the chain is not trusted). In connection with causal ambiguity, Cohen and Levinthal observe [4,p136] "To integrate certain classes of complex and sophisticated technological knowledge into the firms activities, the firm requires an existing internal staff of technologists and scientists who are both competent in their fields and are familiar with the firm's idiosyncratic needs, organizational procedures, routines, complementary capabilities and extramural relationships". In connection with arduous relationships, Cohen and Levinthal observe the potential value of gate keeping or boundary spanning roles for the identification and translation of technical information that is difficult for internal staff to assimilate.

In our extension of the theory we consider the physical capacity to introduce something new. This has dimensions of capital -- being able to invest in new technology or to buy additional capacity, and of time -- organization members making time available to engage with the new thing being introduced (seeing time as a resource), being able to introduce the new thing in a timely way (seeing timing as a strategic variable). For a period of time during the introduction of something new, old products or practices may coexist with the new, requiring additional resources during the transition period. In addition, there may be a period of some disruption and a firm's ability to accommodate that disruption without impacting on the provision of its normal goods and services can be a factor in deciding whether or not to proceed. Some aspects of time were discussed in Cohen and Levinthal's [4] foundation paper - spending time in repetitively using new knowledge will embed it more deeply in the corporate memory. The second component considered is the knowledge needed to understand the significance of this new thing and to understand how to derive value from it. It is this authors view, based on many years of transferring best practice in industry, that the assimilation and transformation stages described by Daghfous [5] are intertwined - becoming competent in the use of the new capability in the current organization context, and that the exploitation stage involves obtaining leverage from the new capabilities in new organizational contexts.

\section{APPLYING THE EXTENDED ABSORPTIVE CAPACITY THEORY}

The question we wish to explore here is does the target RELINK participant firm have the resources and the knowledge to effectively participate in technology- 
enabled large scale collaboration? We argued that there are two primary components of absorptive capacity - available resources and accessible knowledge. Previous studies seem to assume that suitable physical infrastructure exists and have focused on the knowledge component. In the RELINK project, we see that this is not a valid assumption for some of the participants.

In the context of the applications aspect of the reference collaboration support model presented in Figure 1, we aspire to have RELINK project participants access and use a business capability for distributed project management and a technological capability to exchange complex technical data and models between distributed partners. Components of the absorptive capacity project participants would need to acquire are illustrated in Table 1 . Using the entries in Table 1 to frame a series of questions can reveal the current position of a particular firm.

\begin{tabular}{|c|c|c|c|}
\hline \multirow{2}{*}{\multicolumn{2}{|c|}{$\begin{array}{c}\text { Component of Requisite } \\
\text { Absorptive Capacity }\end{array}$}} & \multicolumn{2}{|c|}{ Capability Acquisition Action } \\
\hline & & \multirow{2}{*}{$\begin{array}{c}\text { Business } \\
\text { Capability } \\
\text { - Invest in distributed } \\
\text { project management tools }\end{array}$} & \multirow{2}{*}{\begin{tabular}{l}
\multicolumn{1}{c}{$\begin{array}{c}\text { Technological } \\
\text { Capability }\end{array}$} \\
- Invest in technical data \\
exchange capability \\
- Invest in product and \\
process modeling tools
\end{tabular}} \\
\hline $\begin{array}{l}n \\
y \\
y \\
0 \\
0\end{array}$ & $\begin{array}{l}\text { Investment } \\
\text { capacity (e.g. } \\
\text { borrowing power) }\end{array}$ & & \\
\hline 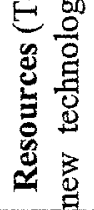 & $\begin{array}{l}\text { Time - Current } \\
\text { resource } \\
\text { commitment (e.g. } \\
\text { people too busy) }\end{array}$ & $\begin{array}{l}\text { - System acquisition and } \\
\text { implementation time } \\
\text { - Application knowledge } \\
\text { acquisition time } \\
\text { - Potential disruption time }\end{array}$ & $\begin{array}{l}\text { - System acquisition and } \\
\text { implementation time } \\
\text { - Application knowledge } \\
\text { acquisition time } \\
\text { - Potential disruption time }\end{array}$ \\
\hline \multirow{3}{*}{ 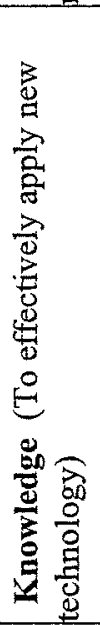 } & $\begin{array}{l}\text { Language } \\
\text { (jargon) and } \\
\text { sensemaking }\end{array}$ & $\begin{array}{l}\text { - Familiarity with } \\
\text { advanced project } \\
\text { management systems } \\
\text { terminology and practices }\end{array}$ & $\begin{array}{l}\text { - Familiarity with technical } \\
\text { data exchange and } \\
\text { modeling tool } \\
\text { systems terminology and } \\
\text { practices }\end{array}$ \\
\hline & $\begin{array}{l}\text { Learning process } \\
\text { skills and } \\
\text { Experimentation } \\
\text { capability }\end{array}$ & $\begin{array}{l}\text { - Understanding how to } \\
\text { operate advanced project } \\
\text { management practices in } \\
\text { the context of the current } \\
\text { business }\end{array}$ & $\begin{array}{l}\text { - Understanding how to } \\
\text { operate data exchange and } \\
\text { modeling systems in the } \\
\text { context of the current } \\
\text { business }\end{array}$ \\
\hline & $\begin{array}{l}\text { Background } \\
\text { competency \& } \\
\text { experience to } \\
\text { obtain leverage } \\
\text { from new } \\
\text { knowledge }\end{array}$ & $\begin{array}{l}\text { - Being able to leverage } \\
\text { project management } \\
\text { knowledge to operate in } \\
\text { an extended enterprise and } \\
\text { to tackle projects with } \\
\text { significant uncertainties in } \\
\text { what to and how to do it. }\end{array}$ & $\begin{array}{l}\text { - Being able to leverage } \\
\text { technical data systems } \\
\text { knowledge to operate in an } \\
\text { extended enterprise and to } \\
\text { develop new internal } \\
\text { business capabilities. }\end{array}$ \\
\hline
\end{tabular}

Table 1: Requisite Absorptive Capacity

Decisions can be made as to whether to (a) integrate with the firm's current position by managing an external interface (a gatekeeper strategy), or (b) whether to enhance the firms ability to interface with more sophisticated systems (acquire absorptive capacity) or some combination of these two things. What emerged in the RELINK project was an information systems strategy where relatively simple IT 
tools were combined with some agreed practices about how they were to be used as follows: firstly, a decision was made to not invest is special purpose project management tools, but to work out how existing tools (e.g. Microsoft Project or Microsoft Outlook) could be utilized within an overarching task definition model. Secondly, data of any kind was to be treated and controlled as a document made available in a password accessible webspace. And finally, project issues could be logged and discussed using a kind of password accessible chat-space

\section{DISCUSSION}

In broad terms, matters that arose in promoting IT support for virtual enterprise operations in the RELINK project were: low levels of acceptance of a broadly descriptive model, with differing perceptions of value of this model (figure 1), and a limited capability to implement such a concept. Two steps were taken to deal with these issues. The first step was to focus on some very specific application (project management and technical data systems) and infrastructure matters, and secondly to use an absorptive capacity view (table 1) to cluster issues so they could be dealt with in the most appropriate way.

Table 1 helps us understand the enormity of the task confronting small firms if they were to all acquire hardware, software and knowledge currently used by some large corporations to implement the requisite functions. By way of example, a single user version of Microsoft Project may be inexpensive, but understanding it is another matter. A reference text called the Microsoft Office Project 2003 Bible contains about 900 pages. The server version of this software that has more collaboration capability also requires other complementary software and hardware, and requires specialist IT skills to support it, all of which becomes quite expensive. The most practical approach was to target a lower level of ICT usage and simpler applications software, achieving total information system requirements (Figure 1 plus Table1) through manual interfaces.

In the context of figure I, it was found that, regardless of the ICT/manual mix in implementation, that some of the suggested reusable components had to be significantly modified. Two areas of figure 1 will be discussed in this regard. A contingency (see figure 1) factor in the RELINK project that differed from past projects was that it attempted to get groups of traditional competitors to collaborate. This influenced some of the roles and social aspects to be managed, and the extent to which knowledge was freely shared, introducing some implicit rules. Some modeling (see figure 1) considerations were that whilst a life-cycle VE model was accepted informally; assumptions about the practicality of a substantial peer network business model were not well founded. Rather than all firms participating in the marketing and bidding processes using IT tools to help draw things together, it was found that a few focal firms had to work face-to-face with the customer. Instead of getting prices and technical inputs from all participants, focal firms had to negotiate the best deal they could, then work out how to manage within the price and schedule requirements agreed. This influenced the nature of project management arrangements and who managed technical data.

Overall we saw that some combination of the business models that made sense and the absorptive capacity of the participants influenced the nature of acceptable 
ICT tools. By way of example, it was anticipated at the start of the RELINK project that some bid development workbench (previously used in other projects) would be helpful in collaboratively developing customer proposals for large projects. This was not the case because of the way bids had to be put to the customer, and because there were concerns about data confidentiality. In the RELINK project, a collection of hub and spoke arrangements was the most commonly observed network configuration, with the hub firms tending to be the larger ones. Some examples of small regional networks were also observed.

The observed cast of generic actors is similar to that observed by CamarinhaMatos and Afsarmanesh [3], characterized as:

- Focal firms that have demonstrated project management skills and can muster useful financial resources

- Technology providers that supply tools and methodologies to the participating firms

- Regional networks that may choose to operate outside their region as a single group

- Communities of Practice that operate across firms to identify collective capabilities and facilitate interaction between firms

- Supporting firms that add capacity by providing access to some of their resources on a flexible basis

In this context, the information systems solution trialed was intended to be usable by the supporting firms, but managed by the focal firms, consistent with Cohen and Levinthal's observation [4 p133]- "At the most basic level, the relevant knowledge that permits effective communication within and across subunits consists of shared language and symbols". Adding consideration of resources into Cohen and Levinthal's [4] theory of absorptive capacity helped direct the technology providers towards open source, freeware based solutions. It was observed that whilst the focal firms had more IT knowledge than most of the supporting firms, both groups had problems assigning time as a resource to system integration or in deciding the most appropriate time to upgrade IT capabilities.

As mentioned in the introduction to this paper, we have previously used activity theory $[7,13]$ to better understand the operation of collaborative ventures by considering the subject that will undertake an activity with an objective in mind, and how this is achieved as governed by the distribution of work, tools available, rules associated with the activity and broader community norms. All of these factors can certainly be identified in the previous discussion - the distribution of work between focal and supporting firms, rules associated with collaboration between competitors, an intention to use ICT tools in some way, and the norms (e.g. firm size) of a particular professional community. In this authors view, consideration of absorptive capacity adds is a consistent way of establishing a firm's ability to participate in a large scale collaboration, which in turn influences the way a collaboration works.

\section{CONCLUDING REMARKS}

In this paper we focus on collaboration technologies, and have considered experience gained in a particular case where a number of difficulties were 
experienced in implementing ideas that had been used elsewhere. The paper draws on the notion of absorptive capacity originally introduced by Cohen and Levinthal [4], which had a focus on a firm's knowledge base facilitating the introduction of new technologies into a firm. We have extended the theory, adding capital and time as key resources in the assimilation of new technology, and also consider the status of a firms knowledge base in terms of three levels of maturity: being able to understand the jargon of something new and make sense of it; being able to effectively use something new in the context of the firm; and obtaining leverage from newly acquired capabilities in an extended context. Some of the SME firms participating in a case study project had a low absorptive capacity that precluded adoption of ICT tools that have been used by large firms. It was also noted that the dominant collaboration business model also influenced the nature of appropriate IT support. The extended notion of absorptive capacity provided a good vehicle for matching information system implementations strategies with user capabilities to meet functional needs.

\section{REFERENCES}

1. Beckett, R.C (2004) "Exploring Virtual Enterprises using Activity Theory", Australian Journal of Information Systems, Vol 12, No 1, pp103-110

2. Beckett, R.C. (2004), "Exploring Sustainable Virtual Enterprises". In "Virtual Enterprises and Collaborative Networks"(Ed L.M. Camarinha-Matos) Kwuhler Academic Publishers, the Netherlands, ISBN 1-4020-8138-3. pp 491-498

3. Camarinha-Matos, L.M, and Afsarmanesh, H (2004) "The Emerging Discipline of Collaborative Networks" in "Virtual Enterprises and Collaborative Networks"(Ed L.M. Camarinha-Matos) Kwuhler Academic Publishers, the Netherlands. ISBN 1-4020-8138-3, pp 3-16

4. Cohen, W.M and Levinthal, D.A. (1990) Absorptive Capacity: A New Perspective on Learning and Innovation. Administrative Science Quarterly, Vol 35 pp 128-152

5. Daghfous, A 2004, 'Absorptive capacity and the implementation of knowledge- intensive best practices' S.A.M. Advance Management Journal, vol. 69, no. 2, pp. 21-27.

6. Dal Zotto, C (2003) "Absorptive Capacity and Knowledge Transfer between Venture Capital Firms and their Portfolio Companies" Druid Summer Conference on Creating, Sharing and Transferring Knowledge, Copenhagen, June $12-14$

7. Engestrom, Y. (1987) "Learning by expanding: an activity-theoretical approach to developmental research" Helsinki; Orienta-Konsultant

8. Mo, J, Beckett, R, and Nemes, L (2005) "Technology Infrastructure for a Virtual Organization of Toolmakers" in Camarinha-Matos, L.M, Afsarmanesh, H and Ortiz, A (Eds) "Collaborative Networks and their Breeding Environments", Springer, New York (ISBN 10 (HB) 0-387-28259-9) pp $493-500$

9. RELINK (2004) hitp:/relink agileserve.com

10. Szulanski, G (1996) "Exploring Internal Stickiness: Impediment to the Transfer of Best Practices Within the Firm" Strategic Management Journal, Vol 17, No 10, pp27-43

11. Teamcenter (2006) "Teamcenter overview: powering innovation with knowledge" wwww.ugs.com (last accessed May 2006)

12. Tsai, W (2001) "Knowledge transfer in intraorganizational networks: Effects of network position and absorptive capacity on business unit innovation and performance" Academy of Management Journal, Vol 44, pp996-1004

13. Vygotsky, L.S. (1978) "Mind and Society" Harvard University Press.

14. Zahra, S.A and George, G (2002) "Absorptive Capacity: A Review, Reconceptualizaton and Extension" Academy of Management Review, Vol 27, No 2, pp 185-203

15. Zwegers A., Tolle M., Vesterager J., (2003). "Virtual Enterprise Reference Architecture and Methodology", Global Engineering and Manufacturing in Enterprise Networks, VTT Symposium 224, 9-10 December, Helsinki, pp.17-

16. Zhou, M, Zheng, J, Williams, A and Alexander, B (2001) "A Web-based Bidding Workbench for Global Manufacturing" in Mo, J.P.T and Nemes, L (Eds) Global engineering, manufacturing and enterprise networks" Kluwer Academic Publishers, Massachusetts (ISBN 0-7923-7358-8) pp 206211 